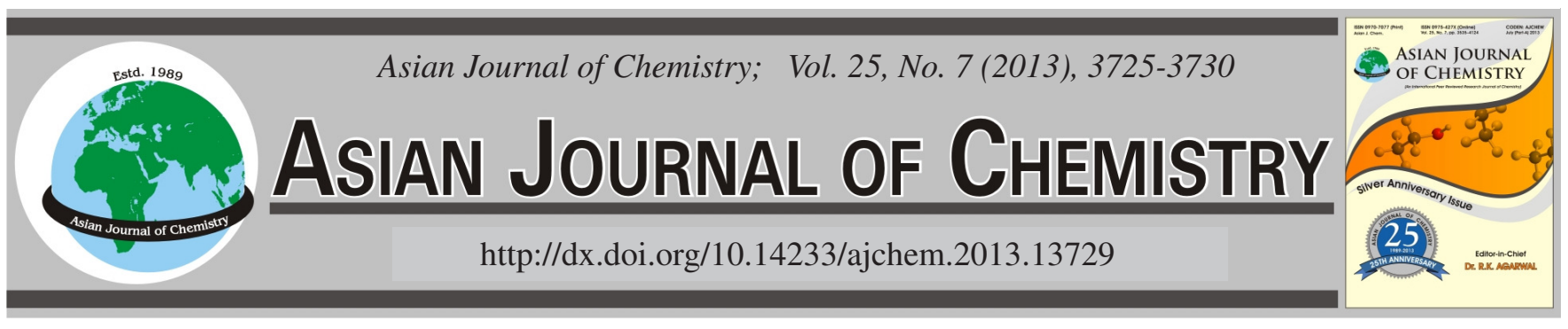

\title{
Chemical Constituents of Heliotropium hirsitutissimum Grauer (Heliotrope) (Sigil otu, Bambil) (Sonnenwende) and Ecotype
}

\author{
Hatice Demiray ${ }^{*}$, Meliha Gemici, Isin Yazici and Fatih Karabey
}

Department of Biology, Faculty of Science, University of Ege, Section of Botany, 35100 Bornova, Izmir, Turkey

*Corresponding author: E-mail: haticedemus@yahoo.com

\begin{abstract}
The aim of this study is to examine the chemical constituents of Heliotropium hirsitutissimum GRAUER naturally spreaded in Denizli and its ecotype spreaded a hotter region in Izmir (Bornova-campus) and to identify them by GC-MS. After the extraction of fresh leaves, one alkaloid and a mixture of phenols, essential oils: 2,3- butanediol, 2-3- dimethyl- (CAS) pinacol (other name: tetramethylethylene glycol), phenol, 4-(3-hydroxy-1-propenyl-2-methyl-(CAS) coniferyl alcohol (other name 4-hydroxy-3-methoxycinnamyl alcohol), 1H-pyrrolizine7-methanol-2,3,5,7,a-tetrahydro-1-hydroxy-(IS-Cis)- (CAS)=heliotridine, Xycaine \$ Aceteamide,2-(diethylamino)-N-(2,6-dimethylphenyl) and 2,6,10,14,18,22-tetracosahexaene (other name: squalene) were identified in the species spreaded naturally in Denizli. Izmir ecotype gave a mixture of essential oils and phenol 1-hexadecanol; tetracosane acid, butyl 2-methylpropyl ester, phenol: phenol, 4,4'-(1methylethylidene)bis-(CAS) 2,2-bis(p-hydroxyphenyl)propane, ethanol, 2-2'-(1-2-ethanediol bis(oxy))bis-(CAS)triethylene glycol, octadecanoic acid (other name stearic acid), 2-hydroxy-1-(hydroxymethyl) ethyl ester (CAS) and 2-Monostearin. The main components of the two ecotypes was 1,2-benzene dicarboxylic acid and hexadecanol. The presence of triethylene glycol was found to be as the significant structural difference of Izmir ecotype. These results indicated that the composition of heliotrops highly dependent on the climate conditions.
\end{abstract}

Key Words: Heliotropium hirsitutissimum, Ecotype, Chemical constituents.

ᄂ _ - - - _ - - - - - - - - - - - - - - - - - - - - - -

\section{INTRODUCTION}

The genus Heliotropium, a known source of pyrrolizidine alkaloids, flavonoids and geranyl aromatic derivatives, is comprised of about 250 species distributed throughout both hemispheres ${ }^{1}$, with 14 species and two of them endemic to Turkey ${ }^{2}$. One of them Heliotropium ferrugineogriseum NAB is an IranoTuranian the other is $H$. haussknechtii BUNGE. Mediterranean element and distributes throughout East Anatolia (mezopotamia) and South Anatolia region, respectively. This erect or decumbent annual or perennial semi shrubby herb and can grow up to $50 \mathrm{~cm}$ high and possesses purple flowers in scorpiod cymes. Leaves are alternate, calix parted, stamens are in the corolla tube and have short filaments, throat scales are absent ${ }^{2}$.

This herbaceous plant is known to contain pyrrolizidine alkaloids (PAs) ${ }^{3-5}$ and has already been reported to be responsible for intoxications of horses, goats and sheep ${ }^{6,7}$.

The Boraginaceae family is well known for containing pyrrolizidine alkaloids (PAs) that are responsible for several cases of human and cattle intoxication resulting in chronic hepatotoxicity. The pyrrolizidine alkaloids also induce important risks of carcinogenicity, mutagenicity and teratogenicity ${ }^{8,9}$.
In this study, essential oil and alkaloid contents of Heliotropium hirsitutissimum naturally spreaded on Denizli and also its ecotype spreaded a hotter region in Izmir (Bornovacampus) were identified by GC-MS. Genus Heliotropium hirsitutissimum has a large distribution area in Turkey as being an South Mediterranean element spreaded also in Bulgaria, Greece, Aegean, N. Africa, Syria and Palestine ${ }^{10}$. Like many of the plants of this geographic area, they characteristically produce a resinous exudate that covers the leaves and stem ${ }^{1}$. These exudates have been associated with a complex defense mechanism. There is experimental evidence indicating that the resins are part of a protective cover that prevents excessive water evaporation $^{11}$. These resins have been proposed to play an extensive role against phytophagous organisms and UV radiation in the range $180-320 \mathrm{~nm}^{12,13}$. Researchers described the isolation and structural elucidation of rel-(8R,9R)carrizaloic acid ${ }^{14}$ (1) 3-[rel-(8R,9R-9-hydroxy-9,13,13trimethyl-12-oxo-10-cyclo-hexenyl)methyl]-4-methoxybenzoic acid, a new compound and three known flavonoids from the resin exudates of Heliotropium huascoense ${ }^{13}$. They have also studied the antifeedant, insecticidal and antifungal effects of $\mathbf{1}$ and its methyl derivative (2) against several divergent 
phytophagous insects (the beetle Leptinotarsa decemlineata, the lepidopteran Spodoptera littora-lis and the aphid Myzus persicae) and plant pathogens (Fusarium moniliforme and Aspergillus niger). The related compound filifolinol ${ }^{15}$, an aromatic geranyl derivative isolated from $H$. filifolium has been included in the biological tests for comparison purposes. The aim of this study is to describe the chemical constituents of $H$. hirsutissimum Grauer, spreads in Denizli, which is hexaploid $(2 \mathrm{n}=48)$ and never occurs in thermal habitats and affinities clearly lie with the annual Heliotropium thermophilum and Izmir ecotype of $H$. hirsutissimum Grauer spreads in a hotter region than Denizli ecotype. Tan et al. ${ }^{16}$, was described $H$. thermophilum as a species new to science and illustrated with its diploid chromosome number of $2 n=16$. It was restricted to the province of Aydin bordering on Denizli in SW Anatolia and was of interest on account of its unusual habitat, which was a geothermal area with ground temperatures of $55-65^{\circ} \mathrm{C}$. Micromorphological, ecological and ecophysiological data for the new taxon have been provided. Ecological isolation has allowed the evolution and differentiation of a new and distinct species $^{16}$.

\section{EXPERIMENTAL}

Plant material: Heliotropium hirsitutissimum was collected during the flowering season in October 2008, in Denizli West Anatolia and also was collected in campus of University of Ege in Izmir and identified by Prof. Dr. Yusuf Gemici from Herbarium Centre of University of Ege.

Extraction and isolation: The resinous exudates of $H$. hirsitutissimum were obtainted by dipping $100 \mathrm{~g}$ of each fresh plant in cold $\mathrm{MeOH}, \mathrm{EtOH}, \mathrm{CHCI}_{3}$, petroleum ether and distilled water for 15-20 times. The extracts were concentrated to afford $172.41 \mathrm{mg}$, $(\mathrm{EtOH}, \mathrm{MeOH}), 200 \mathrm{mg}$ (petroleum ether), $166 \mathrm{mg}\left(\mathrm{CHCl}_{3}\right)$ of residues and concentrates of campus ecotype gave $172.41 \mathrm{mg}(\mathrm{MeOH}), 161.3 \mathrm{mg}(\mathrm{EtOH}), 147 \mathrm{mg}$ $\left(\mathrm{CHCl}_{3}\right)$ residues.

$100 \mathrm{~g}$ of each fresh plant extracted in a blender with 300 $\mathrm{mL}$ cold distilled water and waited for 10 days by shaking sometimes. Then, this samples in water were taken in Clevenger apparatus to being the distillation process obtained distillate were partitionated to with dichloromethane and extracts were evaporated to dryness to affort $0.06 \mathrm{~g}$ for Denizli ecotype and $0.02 \mathrm{~g}$ residues for Izmir (campus) ecotype of plant.

Each residue were placed on $60{ }^{\circ} \mathrm{C}$ water both to add $\%$ $\mathrm{HCl}$ and filitrated partition were extracted with petroleum ether. After separation this mixture alkali watered partition were obtained and $25 \% \mathrm{NH}_{3}$ were added by shaking until $\mathrm{pH}$ were regulated to 13 . This solution was extracted with $\mathrm{CHCl}_{3}$ and total alkaloids were obtained after with anhydrous $\mathrm{Na}_{2} \mathrm{SO}_{4}$ filitration as $3.14 \mathrm{~g}$ from Denizli ecotype and $2.54 \mathrm{~g}$ from Izmir ecotype.

A portion of this resinous residues $(3.14 \mathrm{~g}$ in $\mathrm{MeOH}$ soluble Denizli) was fractioned by flash column chromatography on Silica gel [RP-C18 (25-40 um) Merck], using eluent system of $\mathrm{CH}_{2} \mathrm{Cl}_{2}$ together with increasing amounts of $\mathrm{CH}_{3} \mathrm{OH}$ to obtain 134 fractions, each of $100 \mathrm{~mL}$. The fractions were monitored by TLC on Si gel (Silica Gel 60 F254) using the same solvent systems $\mathrm{C}_{6} \mathrm{H}_{5} \mathrm{CH}_{3}-\mathrm{CH}_{3} \mathrm{OH}-0.1 \mathrm{~mL} \mathrm{NH}$ (95:5),
$\mathrm{C}_{6} \mathrm{H}_{5} \mathrm{CH}_{3}-\mathrm{CH}_{3} \mathrm{OH}-\mathrm{CH}_{2} \mathrm{Cl}_{2}$ (70:10:20), $\mathrm{C}_{6} \mathrm{H}_{5} \mathrm{CH}_{3}-\mathrm{CH}_{3} \mathrm{OH}-$ $\mathrm{CH}_{2} \mathrm{Cl}_{2}$ (50:20:30) and $100 \% \mathrm{MeOH}$ for each of them. Visualization was effected with $\mathrm{H}_{2} \mathrm{SO}_{4}(25 \% \mathrm{v} / \mathrm{v})$ by heating the samples of TLC plates. Same fractions were combined and examined with GC-MS.

GC-MS identification: Shimadzu GCMS QP 5050A System with HP-1 fused silica capillary column ( $25 \mathrm{~m}, 0.32$ mm i.d., $0.17 \mu \mathrm{m}$ film thickness \% dimethylpolysiloxane) was used. Injection heat was 250, inter space heat was 280, ionization mode was EI, energy of electrons were $70 \mathrm{eV}$ and mass space was $40-500 \mathrm{~m} / \mathrm{z}$. Heat was programmed as $80,10,220$ and $5{ }^{\circ} \mathrm{C} / \mathrm{min}, 250{ }^{\circ} \mathrm{C} / 10 \mathrm{~min}$ in helium gase with an fluent rate of $1.2 \mathrm{~mL} / \mathrm{min}$.

\section{RESULTS AND DISCUSSION}

Elution of $2.54 \mathrm{~g}$ residue (Izmir ecotype) with solvent system of Toluene-MeOH-0.1 $\mathrm{mL} \mathrm{NH}_{3}$ (95:5) gave a mixture of essential oils and phenol named: 1,2-benzenedicarboxylic acid diethyl ester; 1,2-benzenedi-carboxylic acid, butyl 2-methylpropyl ester; 4,4-(1-methylethylidene) bis phenol; 1 , 2-benzenedicarboxylic acid, bis(2-ethylhexyl) ester; (0.0050 g) (Fig. 1).

$\mathrm{C}_{6} \mathrm{H}_{5} \mathrm{CH}_{3}-\mathrm{CH}_{3} \mathrm{OH}-\mathrm{CH}_{2} \mathrm{Cl}_{2}$ (70:10:20) gave a mixture of phenols, assential oils and alkaloid: 2-3-butanediol, 2-3dimethyl-(CAS) pinacol; phenol, 4-(3-hydroxy-1-propenyl)2-methoxy-(CAS) coniferyl alcohol; $1 H$-pyrrolizine-7methanol, 2,3,5,7-a-tetrahydro-1-hydroxy-(1S-cis)-(CAS) heliotridine; xycaine (acetamide, 2-(diethylamino)-N-(2,6dimethylphenyl)(CAS)2-(diethylamino)-N-(2,6-dimethyl) (0.0043 g) ( Fig. 2).

$\mathrm{C}_{6} \mathrm{H}_{5} \mathrm{CH}_{3}-\mathrm{CH}_{3} \mathrm{OH}-\mathrm{CH}_{2} \mathrm{Cl}_{2}$ (50:20:30) gave a mixture of essential oils 1-2-benzene dicarboxylic acid, diethyl ester (CAS) ethy phthalate; hexadecanoic acid, methyl ester (CAS) methyl palmitate; 1,2-benzene dicarboxylic acid, bis(2-methy propyl)ester (CAS) isobutylphthalate 1-hexadecanol (CAS) cetal hexacosane (CAS) n-hexacosane; 1,2-benzenedicarboxylic acid, bis(2-ethylhexyl) ester (CAS) bis(2-ethyhexyl)phthalate; 2,6,10,14,18,22-tetracosahexaene, 2,6,10,15,19,23hexamethyl-(CAS) squalene from Denizli ecotype $(0.0311 \mathrm{~g})$ (Fig. 3).

The elute obtained with $\mathrm{C}_{6} \mathrm{H}_{5} \mathrm{CH}_{3}-\mathrm{CH}_{3} \mathrm{OH}-0.1 \mathrm{~mL} \mathrm{NH}$ (95:5) gave a mixture of essential oils named ethanol, 2,2(1,2-ethanediolbis(oxyl))bis-(CAS) trietlhylene glycol; 2,5,8,11,14-pentaoxa hexadecane-16-ol (CAS) pentaethylene glycol monomethyl ether; 9-octadecenamide, (Z)-(CAS) oleoamide (Fig. 4).

$\mathrm{C}_{6} \mathrm{H}_{5} \mathrm{CH}_{3}-\mathrm{CH}_{3} \mathrm{OH}-\mathrm{CH}_{2} \mathrm{Cl}_{2}$ (70:10:20) gave a mixture of assential oils and phenol 1-hexadecanol (CAS) cetal; tetracosane acid, butyl 2-methylpropyl ester (CAS) N-butyl isobutyl phthalate, phenol, 4,41-(1-methylethylidene)bis(CAS) bisphenol A(p,p-isomer) (Fig. 5).

$100 \%$ Methanol gave a mixture of essential oils named 1,2-benzenedicarboxylic acid, diethyl ester (CAS) ethyl phthalate; ethanol, 2,2-(1,2-ethane diylbis (oxy)) bis-(CAS) triethylene glycol; 2,5,8,11,14-pentaoxahexadecan-16-ol (CAS) pentaethylene glycol monomethyl ether; 9-octadecenamide, (Z)-(CAS) oleoamide; octadecanoic acid, 2-hydroxy1-(hydroxymethyl) ethyl ester (CAS) 2-monosterain from Izmir ecotype (Fig. 6). 


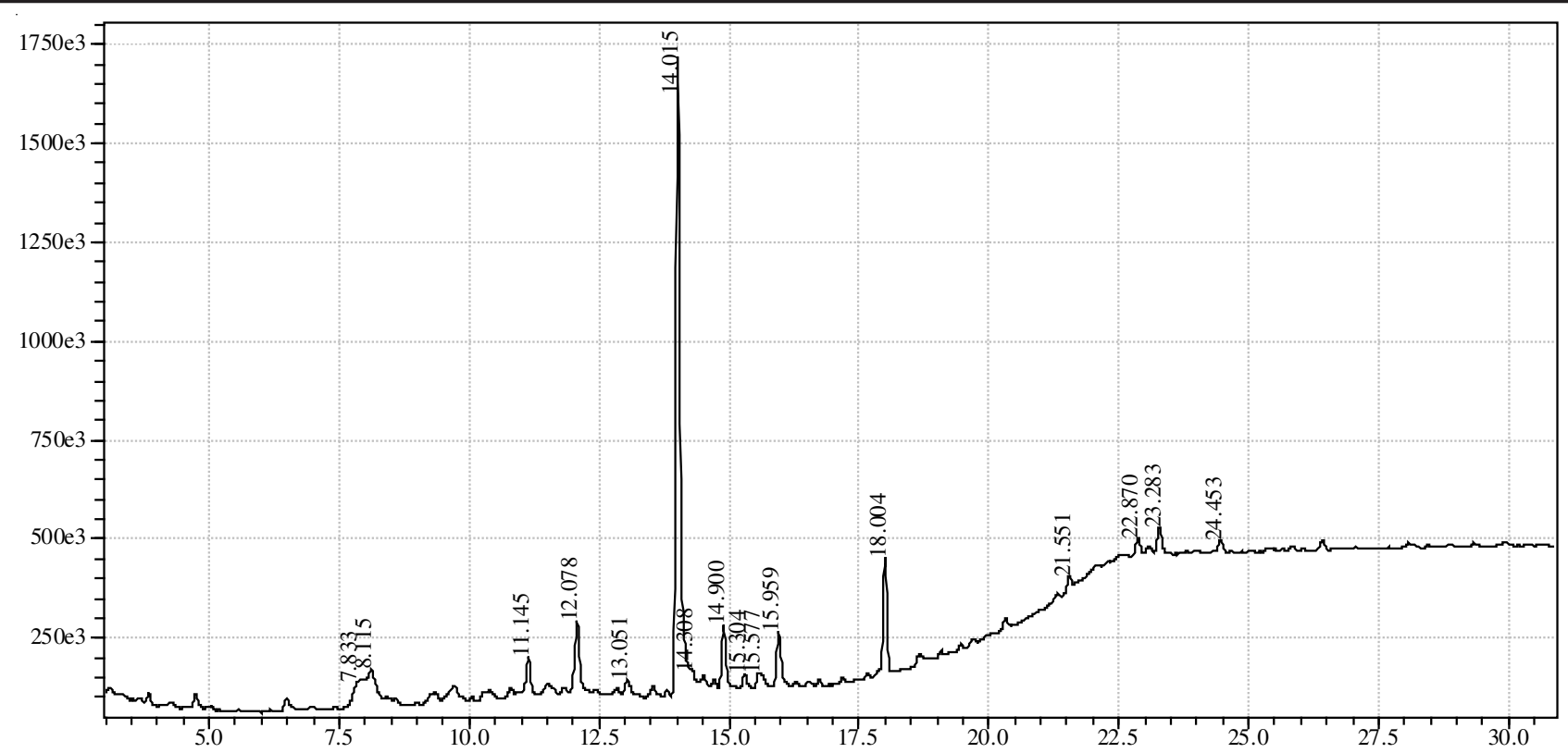

Fig. 1. Chromatograms spectra of Denizli 1 (toluene + methanol $+0.1 \mathrm{~mL} \mathrm{NH}_{3}$ )

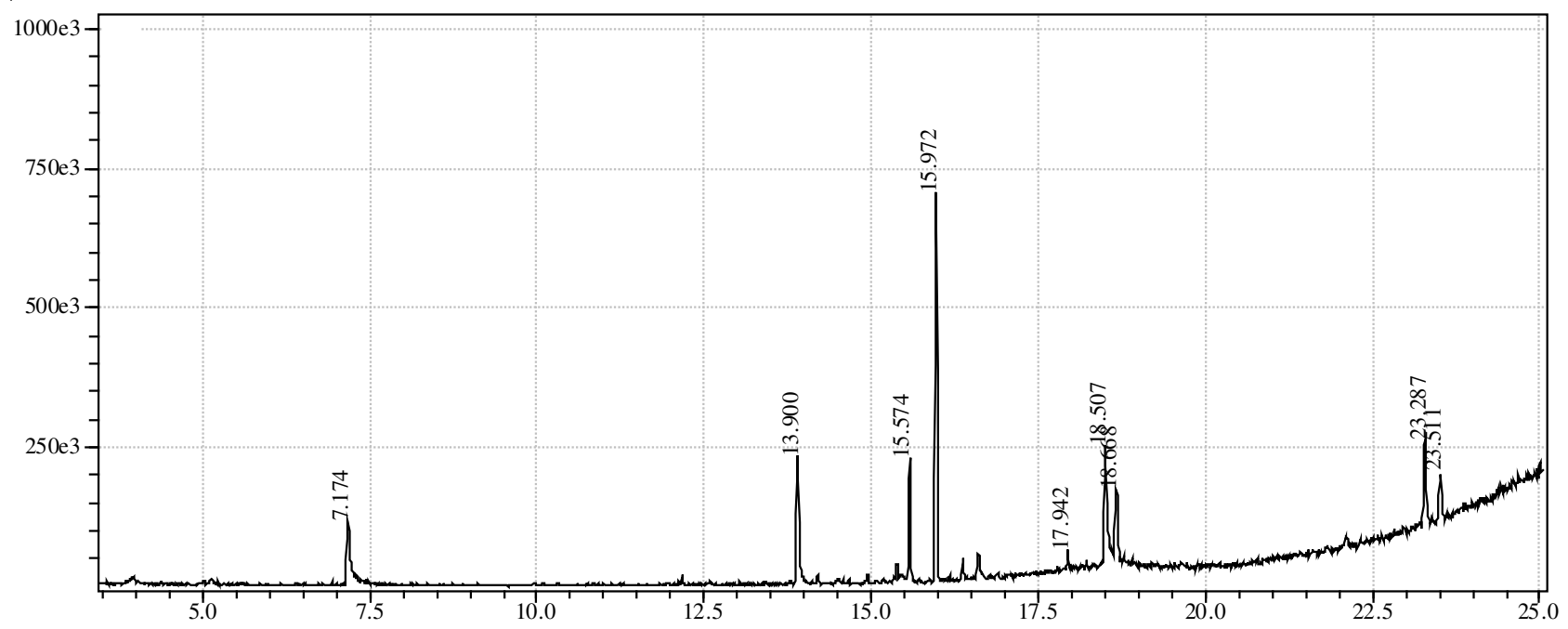

Fig. 2. Chromatograms spectra of Denizli 2 (toluene + methanol + dichloromethane 70:10:20)

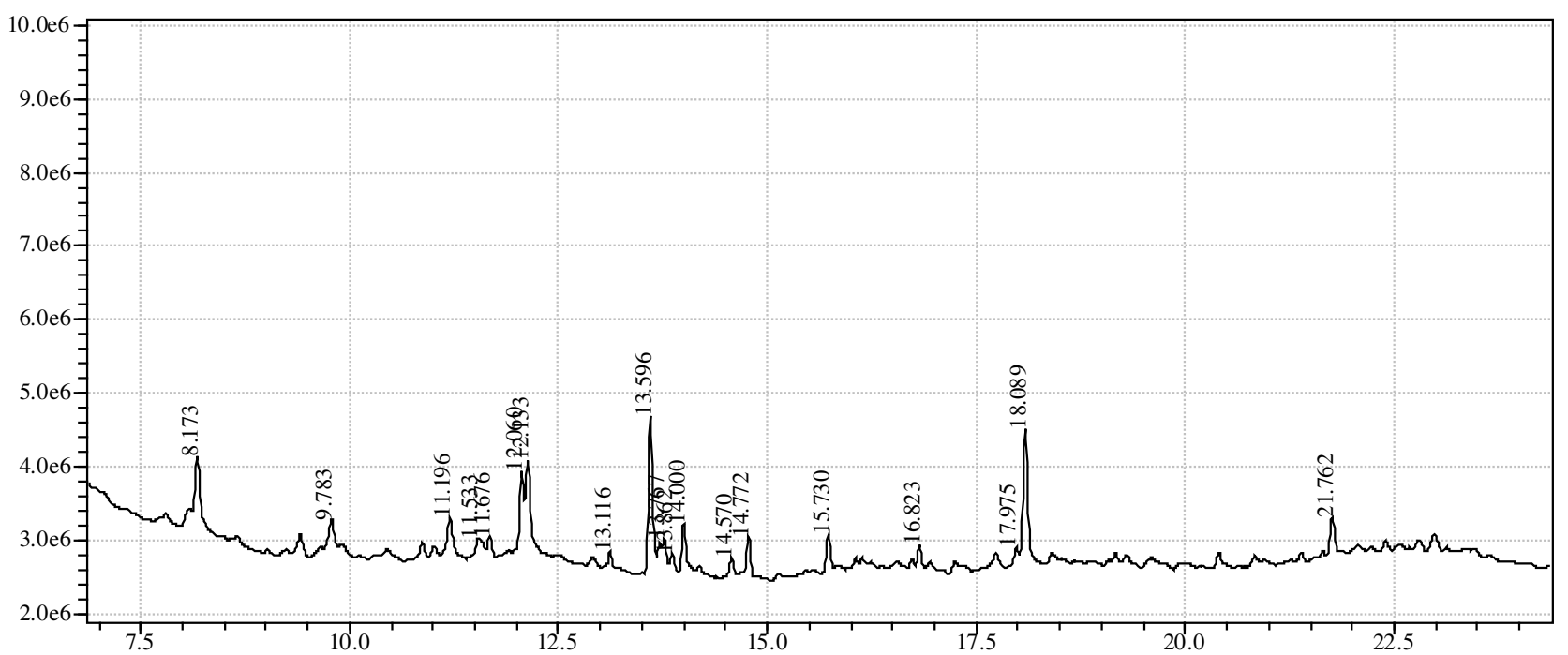

Fig. 3. Chromatograms and spectra of Denizli 3 (toluene + methanol + dichloromethane 50:20:30) 


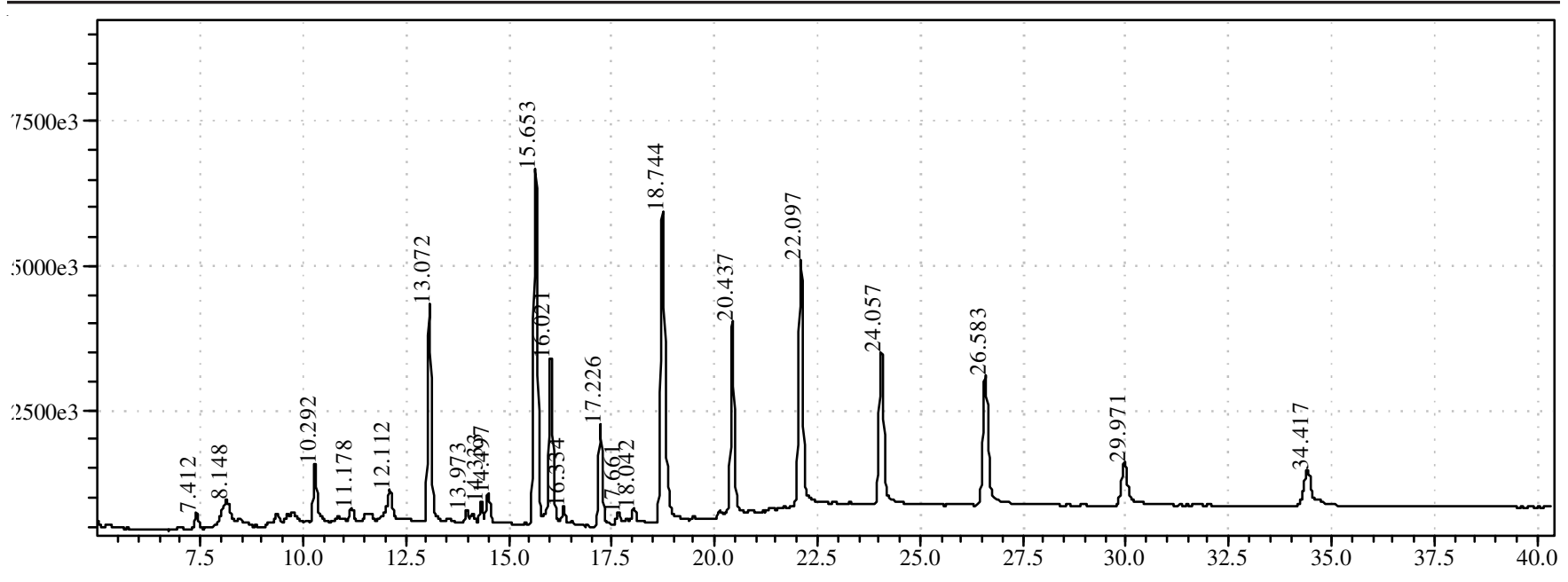

Fig. 4. Chromatograms and spectra of Kampus 1 (toluene + methanol $+0.1 \mathrm{~mL} \mathrm{NH}_{3}$ )

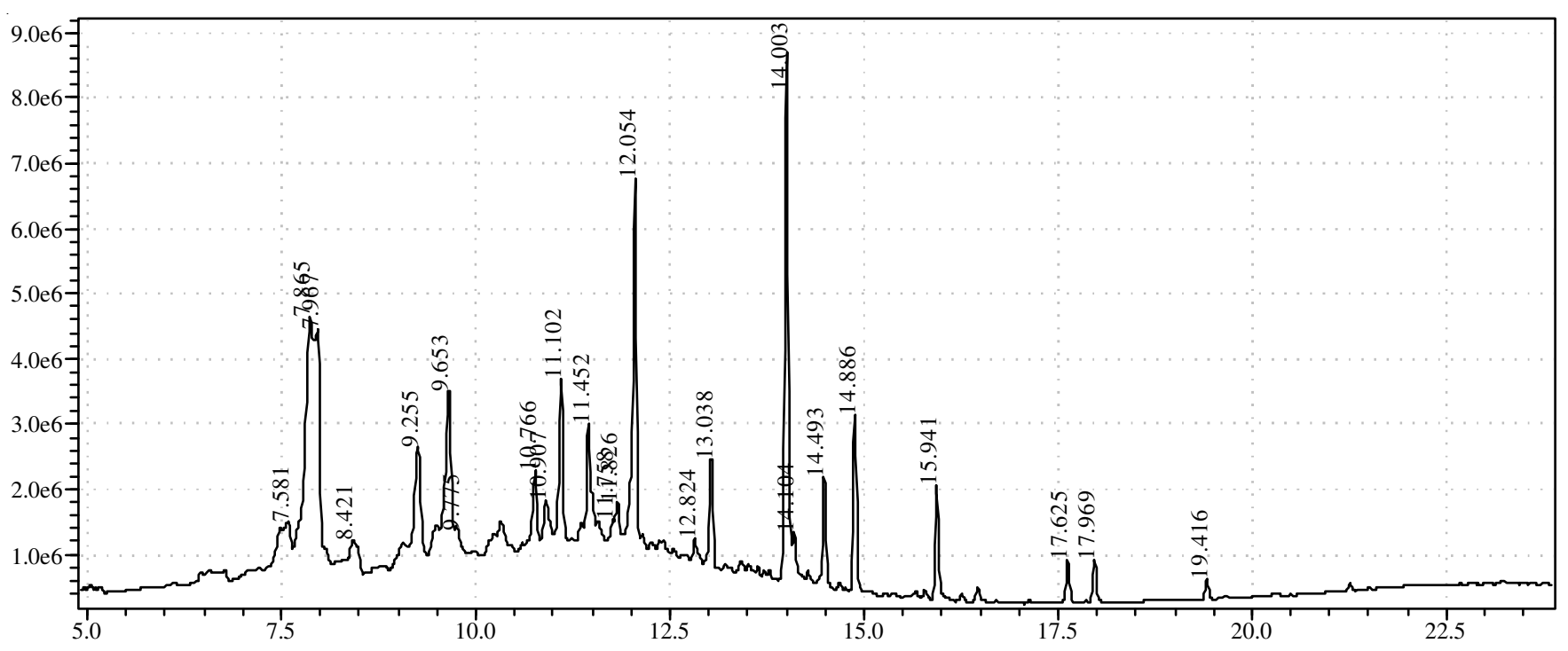

Fig. 5. Chromatograms and spectra of Kampus 2 (toluene + methanol + dichloromethane 70:10:20)

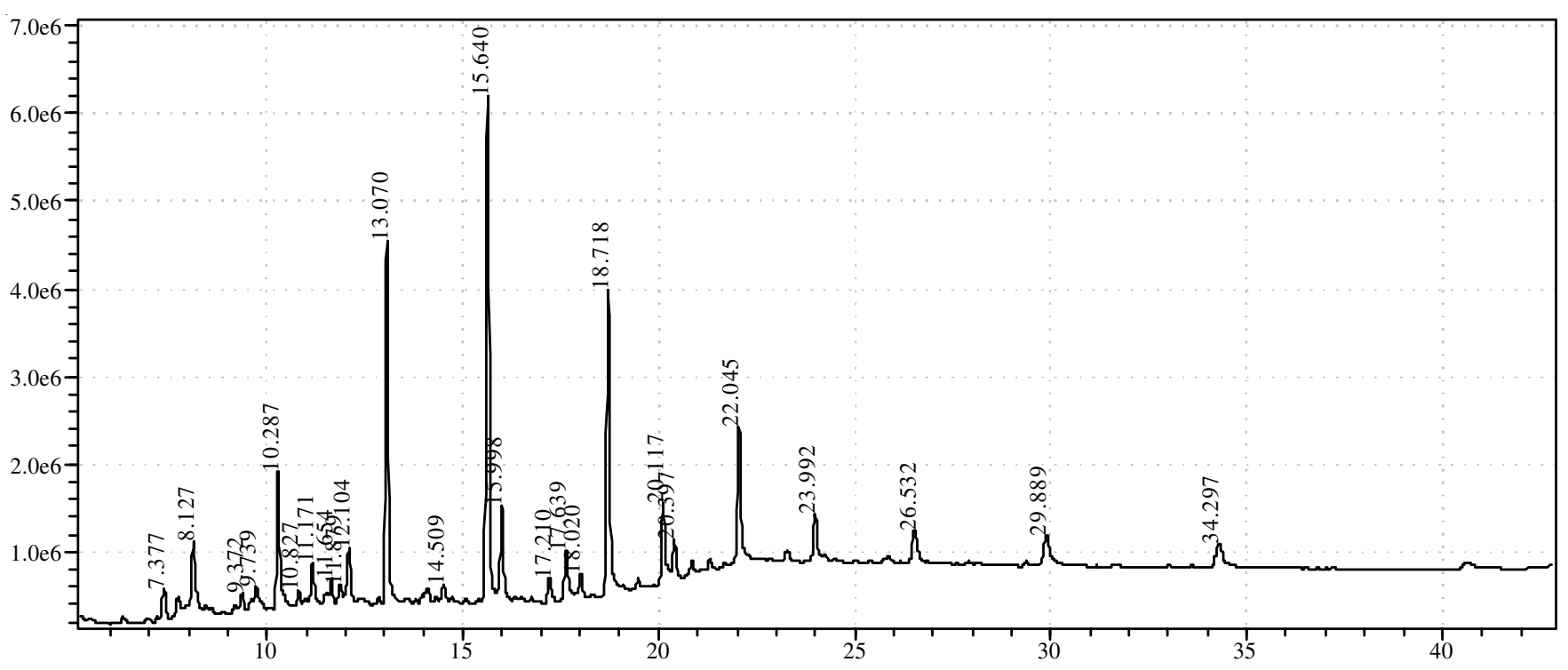

Fig. 6. Chromatograms and spectra of Kampus 3 (100\% methanol) 
Denizli ecotype: 1-2-Benzenedicarboxylic acid di-ethyl ether (other names: phthalic acid). 1-2-Benzenedicarboxylic acid (other names: phthalic acid). Buthyl 2-methyl propyl ester (other names: phthalic acid). Phenol 4.4 1-(1-methylethyl dene). 1-2-Benzenedicarboxylic acid bis(2 ethylhexyl)ester (other names: phthalic acid). 2,3-Butanediol, 2-3-dimethyl(CAS) pinacol (other name: tetramethylethylene glycol). 4- (3-Hydroxy-1-propenyl-2-methyl-(CAS) coniferyl alcohol (other name 4-hydroxy-3-methoxycinnamyl alcohol). $1 \mathrm{H}$ Pyrrolizine-7-methanol-2,3,5,7, $\alpha$-tetrahydro-1-hydroxy-(IScis $)-(\mathrm{CAS})=$ heliotridine. Xycaine [aceteamide, 2 -(diethylamino)N-(2-6-dimethyl)]. Hexadecanoic acid (other name: palmitic acid). Methylester (CAS) methyl palmitate. 1-Hexadecanol (CAS)cetal. Hexacosane (CAS) $n$-hexacosane. 2,6,10,14,18,22Tetracosahexaene(Other names: squalene). 2,6,10,15,19,23Hexamethyl-(CAS) squalene.

Izmir (campus) ecotype: Ethanol, 2-21-(1-2-ethanediol bis(oxy)) bis(CAS) triethylene glycol. 2,5,8,11,14 Pentaoxahexadecan-16-ol (CAS) pentaethylene glycolmonomethyl ether. 9-Octadecenamide, (Z)-(CAS) oleoamid. 1-Hexadecanol (CAS) cetal. Tetracosane(CAS) $n$-tetracosane, 1,2-benzedicarboxylic acid diethyl ester. 2,2'-(1-2-Ethanediyl bis(oxy)) bis-(CAS) triethylene gylycol. 2,5,8,11,14Pentaoxohexodecan-16-ol (CAS) pentaethylene glycol monometylether. 9-Octadecenamide, (Z)- (CAS) oleoamid. Octadecanoic acid (other name stearic acid). 2-Hydroxy-1(hydroxymethyl) ethyl ester (CAS) 2-monostearin, phenol, 4,4'-(1-methylethylidene) bis-(CAS) 2,2-Bis( $p$-hydroxyphenyl)propane, tetracosane(CAS) $n$-tetracosane

\section{TABLE-1}

RETENTION TIMES AND RELATIVE PER CENT OF CHROMATOGRAMES AND SPECTRUMS

\begin{tabular}{cc|cc}
\hline Retention time & Relative $(\%)$ & Retention time & Relative $(\%)$ \\
\hline 8.148 & 1.58 & 18.745 & 15.36 \\
10.292 & 2.56 & 20.437 & 8.07 \\
12.112 & 1.14 & 22.097 & 11.62 \\
13.072 & 8.77 & 24.057 & 7.30 \\
14.497 & 1.22 & 26.583 & 7.32 \\
15.653 & 15.39 & 29.971 & 2.55 \\
16.021 & 7.54 & 34.418 & 2.05 \\
17.226 & 4.13 & - & - \\
\hline
\end{tabular}

It should be noted that the experimental RI values for volatile oil compounds were different from the literature values $^{17}$ e.g., 1,2-benzene dicarboxylic acid was the main component of the two ecotypes and hexadecanol was the major constituent instead of 1-dodecanol by Machan et al. ${ }^{17}$. But the presence of triethylene glycol was found to be as the significant structural difference of Izmir ecotype.

Heliotridine, a novel pyrrolyzidinediols ${ }^{18}$ that have in common the azacicyclo (3:3:0) octane ring system have been reported to act as antitumor, hypotensive, local anesthetic, antispasmotic, antiflammatory, carcinogenic or hepatotoxic agents ${ }^{19}$ has been isolated as a major product of $H$. hirsutisissimum Denizli ecotype from the aerial parts of plant. Heliotridine is the most common necine base in American and Indian Heliotropium spp..$^{20}$, probably found free together with the esters, e.g., lasicarpine and heliosupine ${ }^{21}$.
Between the 20 Heliotropium species collected in Mexico and USA and one species from Spain, heliotridine was found only in one species ${ }^{22,23}$. H. bovei, H. floridum, H. megalantum, $H$. sinuatum, $H$. strygosum was reported to contain heliotridine ${ }^{24}$, phenol, 4,4'-(1-methylethylidene)bis-(CAS) 2,2-Bis( $p$-hydroxyphenyl)propane was present in a higher ratio $(57.06 \%)$ in Denizli ecotype rather than Izmir ecotype $(15.73 \%)$. Denizli ecotype was rich in phenol contents with the presence of additive phenol, 4-(3-hydroxy-1-propenyl- 2methyl-(CAS) coniferyl alcohol content

Isoprenoid compounds like as isoprene, monoterpenes and sesquiterpenes are synthesized and emitted by some plant species (e.g., Quercus ilex), but not all plant species have this ability ${ }^{25}$. Recent work indicated that isoprene acted on photosynthetic membranes to protect against termal damage ${ }^{26}$. Monoterpenes and sesquiterpenes which have diverse ecological functions, such as antiherbivory and antimicrobial defence or pollinator attraction ${ }^{27}$ are non essential isoprenoids. Besides these abscicic acid (C15), gibberellic acid (C20) as being hormones and sterols and carotenoids are essential isoprenoid compounds which have protective functions in photosynthetic systems. Plant triterpenes, such as oleanolic acid ${ }^{28,29}$, ursolic $\operatorname{acid}^{29}$, a-hederin ${ }^{28,29}$ and glycyrrhizin ${ }^{30}$ are aliphatic polycyclic compounds based on a skeleton with 30 carbon atoms and they are synthesized from squalene as the precursor ${ }^{31}$. Squalen, a triterpene sterol, was found in Denizli ecotype of $H$. hirsutisissumum. This compound first isolated from fish liver oils but is also found in plant oils and mammalian fats ${ }^{32}$. Because of its unsaturated bonds, the squalene structure features reactivity and thermolability ${ }^{33}$. So, we can explain the reason of $H$. hirsutissimum Grauer affinities why clearly lie with the annual $H$. thermophilum, which spreads in a geothermal area with ground temperatures of $55-65^{\circ} \mathrm{C}$

$n$-Tetracosane found in Izmir ecotype of $H$. hirsutisissumum has been identified in the unsaponifiable matter of a plant wax and a fatty oil. An isotope labeling study in humans ${ }^{34}$ concluded that the fraction of dietary stearic acid oxidatively desaturated to oleic acid was 2.4 times higher than the fraction of palmitic acid analogously converted to palmitoleic acid. Also, stearic acid was less likely to be incorporated into cholesterol esters. In epidemiologic and clinical studies stearic acid was associated with lowered LDL cholesterol in comparison with other saturated fatty acids ${ }^{35}$. These findings may indicate that stearic acid is healthier than other saturated fatty acids. Hydrogenation of palmitic acid yields cetyl alcohol, which is used to produce detergents and cosmetics. The underlying method of drug delivery is similar to that used with decanoic acid found in Izmir ecotype also to deliver long-acting depot medication, in particular, neuroleptics such as haloperidol decanoate.

Application of earlier drought stress induction by polyethylene glycol solutions of elevated strength (8 and $16 \%$ ) severely reduced growth and yield attributes of soybean when compared to its later application. Furthermore, increased in the endogenous contents of jasmonic acid, salicylic acid and absissic acid in response to drought stress demonstrated the involvement of these hormones in drought stress resistance ${ }^{36,37}$. The most common dehydration method used for natural gas is 
the absorption of water vapor in the liquid desiccant, triethylene glycol. For this reason, the presence of triethylene glycol, pentaethylene glycol monometylether in Izmir ecotype of $H$. hirsutisissumum revealed that the plant was under drought stress.

\section{REFERENCES}

1. L. Villarroel, R. Torres, A. Urzu'a, M. Reina, R. Cabrera and A Gonza'lez-Coloma, J. Nat. Prod., 64, 1123 (2001).

2. P.H. Davis, Flora of Turkey and East Aegean Islands, Univ. of Edinburg, Vol. 3 (1982).

3. K.P. Tiwari and M. Masood, Proc. Nat. Acad. Science (India) A, 47, 72 (1977).

4. S. Mohanraj, P. Kuanthhaivel, P. Subramanian and W. Herz, Phytochemistry, 20, 1991 (1981).

5. A.M. Rizk, F.M. Hammonda and N.M. Hassan, Qatar Univ. Sci. J., 11, 113 (1991)

6. D.H. Abu, S.E. Adam and G. Tartour, Br. Veterinary J., 138, 463 (1982).

7. J.H. Creeper, A.A. Mitchell, T.F. Jubb and S.M. Colegate, Aust. Veterin. J., 77, 401 (1999).

8. L.B. Bull, C.C.J. Culvenor and A.T. Dick, The Pyrrolizidine Alkaloids, North-Holland Publishing Company, Amsterdam (1968).

9. H. Wiedenfeld and J. Edgar, Phytochem. Rev., 10, 137 (2011).

10. Anonymous, Tubives (2012), Turkish Plants Data Service Online at: http://turkherb.ibu.edu.tr.

11. B. Dell and A.J. McComb, Adv. Bot. Res., 6, 277 (1978).

12. R.G. Kelsey, G.W. Reynolds and E. Rodriges, In eds.: E. Rodriguez, P. Healy and L Metha, In Biology and Chemistry of Plant Trichomes, Planum Press: New York; Ch. 8, pp. 187-241 (1984).

13. N.D. Johnson, Biochem. Syst. Ecol., 11, 211 (1983)

14. L. Villarroel, R. Tórres, A. Urzua, B. Modak, J. Henriquez and I. Salgado, Rev. Latinoamer. Quím., 25, 109 (1997).

15. R. Torres, L. Villarroel, A. Urzuá, F. Delle Monache, G. Delle Monache and E. Gacs-Baitz, Phytochemistry, 36, 249 (1994).
16. K. Tan, A. Çelik, Y. Gemici, M. Gemici and H. Yildirim, Adv. Sci. Lett., 1, 132 (2008).

17. T. Machan, J. Korth, S. Liawruangrath and S.G. Pyne, Flavour Fragr. J., 21, 265 (2006).

18. A.R. Chamberlin and J.Y.L. Chung, Am. Chem. Soc., 105, 11 (1983).

19. C.K. Atal, Prog. Chem. Org. Nat. Prod., 41, 115 (1978).

20. A.F.M. Rizk, Naturally Occurring Pyrrolizidine Alkaloids, CRC Press, Boca Raton (1991)

21. H. Baxter, J.B. Harborne and G.P. Moss, Phytochemical Dictionary. A Handbook of Bioactive Compounds from Plants, Taylor and Francis ISBN: 0-203-48375-8, edn. 2 (2009).

22. J.L. Catalfamo, M.W. Frohlich, W.B. Martin Jr. and H. Brecta, Phytochemistry, 21, 2677 (1982).

23. H. Birecka and J.L. Catalfamo, Phytochemistry, 21, 2645 (1982).

24. Atta-ur-Rahman, Studies in Natural Products Chemistry, V 31. Elsevier B.V., The Netherlands (2005).

25. M. Susan and J. Peñuelas, Trends Plant Sci., 10, 9 (2005).

26. E.L. Singsaas and T.D. Sharkey, Plant Cell Environ., 23, 751 (2000).

27. J. Kesselmeier and M. Staudt, J. Atmos. Chem., 33, 23 (1999).

28. Y. Liu, H. Kreppel, J. Liu, S. Choudhuri and C.D. Klaassen, J. Pharmacol. Exp. Ther, 266, 400 (1993).

29. J. Liu, Y. Liu, Q. Mao and C.D. Klaassen, Fundam. Appl. Toxicol., 22, 34 (1994).

30. Z.A. Shaikh, T.T. Vu and K. Zaman, Toxicol. Appl. Pharmacol., 154, 256 (1999).

31. S.B. Mahato, S.K. Sarkar and G. Poddar, Phytochemistry, 27, 3037 (1988).

32. O.J. Catchpole, J.C. von Kamp and J.B. Grey, Ind. Eng. Chem. Res., 36, 4318 (1997).

33. A. Pietsch and P. Jaeger, Eur. J. Lipid Sci. Technol., 109, 1077 (2007).

34. E.A. Emken, Am. J. Clin. Nutri., 60, 1023S (1994).

35. J.E. Hunter, J. Zhang, K. Etherton and M. Penny, Am. J. Clin. Nutr., 91, 46 (2010)

36. M. Hamayun, S.A. Khan, Z.K. Shinwari, A.L. Khan, N. Ahmad and J.L. In, Pak. J. Bot., 42, 977 (2010).

37. A. Balasubramani and G. Balasubramani, J. Biotechnol. Mol. Biol. Rev., 6, 31 (2011). 